THURSDAY, APRIL 27,1876

\section{"SCIENTIFIC WORTHIES"}

\section{Vit.-Sir Charles Wheatstone, Born February} I8oz, Died October I9, I875

CI HARLES WHEATSTONE was the son of a musicseller at Gloucester, where he was born in February 1802 , and was educated at a private school in that city. His father afterwards came to London, where he became a teacher of the flute. He had, we bel eve, some share in the musical education of the Princess Charlotte, a fact of which he was never tired of boasting. In 1823 young Wheatstone removed to London and commenced business as a musical instrument maker, and in the same year made what was probably his first contribution to scientific literature in a paper entitled "New Experiments on Sound," contributed to Thomson's "Annals of Philosophy." In I 827 he contributed to the Quarterly Fournal of Science an account of "Experiments on Audition," and a description of the beautiful toy known as the Kaleidophone. In ${ }^{8} 832$ he read an important paper to the Royal Society, "On the Acoustic Figures of Vibrating Surfaces." In this memoir the author gave for the first time the laws of formation of the varied and beautiful figures discovered by Chladni. He continued for several years to devote his attention to Sound, and subsequently to Light. He was appointed Professor of Natural Philosophy in King's College, London, in 1834 , and in the same year made his celebrated experiments on the velocity of an clectric discharge by the aid of revolving mirrors. Wheatstone does not seem to have lestured regularly at King's College, and many of his discoveries were described to the world by Faraday at the Royal Institution. Indeed he was not well adapted for public lecturing; he was so nervous that even in a very small company he usually sat silent. Though his discoveries have become of such immense practical importance, Wheatstone himself was far from being a practical business man; on this account he often failed to reap the substantial fruit of his discoveries. Wheatstone was married on Feb. I2, 1847.

Wheatstone's name is intimately connected with the early history of Spectrum Analysis. In a paper read in 1835, "On the Prismatic Analysis of Electric Light" at the Dublin meeting of the British Association, he announced the existence of rays of definite refrangibility, cmitted in the volatilisation of metals by the electric spark. He showed that the spectrum of the electric spark from different metals presented eacin a definite series of lines differing in colour and position from each other, and that these appearances afforded the means of distinguishing the smallest fragment of one metal from that of another. "We have here," he wrote, "a mode of discriminating metallic bodies more readily than that of chemical examination, and which may hereafter be employed for useful purposes." These last words furnish the keynote to all Wheatstone's work ; however valuable may be the services he has rendered to pure science, his great ultimate aim was the useful and practical. It was at the' meeting of the British Association in 1838 that he described and exhibited the newly-invented stereoscope, and at the 1848 meeting he described his "polar clock," an instrument for ascertaining the time by means of the change in the plane of polarisation of the light of the sky in the direction of the pole. One of these instruments, we believe, has been sent out with the Arctic Expedition. Wheatstone's description of the rheostat, and of the wellknown "bridge" which bears his name, is printed in the Transactions of the Royal Society for 1843 . Indeed, it is a popular error to suppose that Wheatstone's scientific fame rests solely on his connection with the electric telegraph ; he would have deserved an honourable place in the annals of science had this practical application of electricity been yet undiscovered. In the Catalogue of the Royal Society alone will be found the titles of upwards of thirty papers by him, not to mention many others scattered about in various publications.

The President of the Italian Society ot Science, of which he was made an honorary member in 1867 , said, in conferring the honour, that the applications of the principle of the rotating mirror are so important and so various that this discovery must be considered as one of those which have most contributed in these latter times to the progress of experimental physics. "The memoir on the measure of electric currents and all questions which relate thereto and to the laws of $\mathrm{Ohm}$ has powerfully contributed to spread among physicists the knowledge of these facts and the mode of measuring them with an accuracy and simplicity which before we did not possess. All physicists know how many researches have since been undertaken with your rheostat and with the- so-called 'Wheatstone Bridge,' and how usefully these instruments have been applied to the measurement of electric currents, of the resistance of circuits, and of electro-motive forces."

With regard to the scientific value of the revolving mirrors, Mí. Dumas spoke as follows in the address which he gave at the obsequies of Wheatstone in Paris:- "This admirable method enabled Arago to trace with a certain hand the plan of the fundamental experiment which should decide whether light is a body emanating from the sun and stars or an undulating movement excited by them. Executed by an accomplished experimenter, it proved that the theory of emission was wrong. This method has then furnished to the philosophy of the sciences the certain basis on which rest our ideas of the nature of the forces, and especially of that of light. By means of this or some other analogous artifice, we can even measure the speed of light by experiments purely terrestrial, which, pursued by an able physicist, have guided the measure of the distance between the earth and the sun."

As to Wheatstone's connection with the electric telegraph, it is unnecessary for us here to speak, as this was so fully gone into in the series of articles on "The Progress of the "Telegraph," in vols. xi. and xii. of NATURE. De la Rive, in his "Treatise on Electricity," (Part VII., Chap. I.), states so fairly Wheatstone's connection with telegraphy, that we quote here what he says :-

"The philosopher who was the first to contribute by his labours, as ingenious as they were persevering, in giving to electric telegraphy the practical character that it now 
possesses, is, without any doubt, Mr. Wheatstone. This illustrious philosopher was led to this beautiful result by the researches that he had made in 1834 upon the velocity of electricity-researches in which he had employed insulated wires of several miles in length, and which had demonstrated to him the possibility of making voltaic and magneto-electric currents pass through circuits of this length. It was in 1837 , in the month of June, that Mr. Wheatstone took out his first patent. He first employed five conducting-wires, between two distant stations, acting upon five magnetised needles, the movements of which, being combined two and two, were enabled to produce several different signs. Mr. Wheatstone, at this time, entered into partnership with Mr. Cooke, who had likewise devised an ingenious telegraphic apparatus founded upon the same principles. The English philosophers, from the very first, had added to the telegraph-properly so called-an apparatus intended to call the attention of the observers, and designated under the name of Alarm. .. The principle upon which this alarm is founded includes an immense number of applications, for it enables man to put in action-at any distance whatever-all the forces of mechanics, in an instantaneous manner. Indeed, more recently. Mr. Wheatstone applied it to the construction of his dial telegraph; and it is the same principle which serves as the basis of Morse's telegraph, invented at nearly the same period."-De la Rive, Part VII. Chap. I.

We may repeat here a fact which does not appear to be generally known or recognised, that Wheatstone was the first suggester and worker at submarine telegraphy. From documents before us we learn that so early as $I 837$ be was thinking múch on and was greatly interested in the subject; and in February, 1840 , he stated his opinion before a Select Committee of the House of Commons as to the practicability of establishing electric communication by means of a cable between Dover and Calais.

Wheatstone's applications of electricity were almost innumerable. His electric clocks are well known; various electric registers were invented by him, one especially for recording a variety of meteorological data, and another, which acts as a chronoscope to register the velocity of a bullet. Indeed, his ingenuity was marvellous, and, as we have already hinted, there are doubtless many useiul inventions due to him, of which he has reaped neither the profit nor the credit.

Wheatstone received many "honours" during his lifetime. He was made a Fellow of the Royal Society in 1836 , in 1868 he was knighted, in 1873 he was elected a. foreign member of the Paris Academy, and had altogether upwards of thirty foreign distinctions. The following estimate of Wheatstone and of his contributions to science is from the pen of Signor Paul Volpicelli, the distinguished Italian electrician.

The Academy of Sciences of the Institute of France, at its séance of October 18, 1875, was informed by the perpetua ${ }^{1}$ secretary, M. Dumas, that the illustrious English physicist, Charles Wheatstone, was seriously ill in Paris at the Hotel du Louvre. By the 17th of the month, however, fears for the safety of that savant were well nigh vanished, and it was believed that he would soon be completely restored to health. The hope unhappily proved fallacious; an aggravation having occurred in the pneumonitis, which was thought to have been overcome, carried off that distinguished physicist on the I th of the month from bis friends and from science.

Our Reale Academia dei Lincei was profoundly afflicted at this irreparable loss, which deprived it for ever of one of the most celebrated of its foreign correspondents, who was and will continue to be one of the proudest and most pure scientific glories, not only of England, but of the whole civilised world, since science does not know nation. alities, but belongs to all countries.

The brilliant Wheatstone inevitably became possessed of all those honours which science is wont to confer on her eminent votaries, and in 1875 he obtained from the Academy of Sciences of the Institute of France a title of the highest distinction, that, viz., of one of the eight Foreign Associates. . Among the cultivators of physics the name of Wheatstone will never be forgotten; neither the present nor the future can forget his rare penetration, the inventiveness of his genius, his discoveries, and the uncommon ability with which he reproduced in machines the phenomena of nature.

His name will be as that of a star to whose light will turn the minds of those who desire to comprehend the progress of physical doctrine. In doing honour to the memory of this our illustrious foreign correspondent, it will be best to record his scientific labours, which are all of the highest interest.

In the present short obituary notice we shall merely give a rapid sketch of the principal physical researches of the illustrious deceased.

Our countryman, Leonardo da Vinci, in 1500 , or thereabouts, conceived and was the first to affirm, that from a picture it was not possible to obtain the effect of relief. But Wheatstone, reflecting profoundly in 1838 , on the physiology of vision, invented the catoptric stereoscope, with which he philosophically solved the problem of the optical and virtual production of relief.

This instrument was a converted dioptric of the father of modern optics, the distinguished Brewster, and at the same time was more simple, more popular, and more elegant. Continuing to study the physiology of vision, Wheatstone succeeded in constructing the diaphragmatic stereoscope, i.e. without mirror and without lenses, but merely with a diaphragm. With this instrument there could be received coexistently on the retina three images, two, viz., one photographic, and ane in relief, produced from the first two.

The diaphragmatic stereoscope manifested, better than the two others, the physiology of vision; it was published in the "Atti dell. Academia pontificia dei Nuovi Lincei," t. vii. p. 219, and in the work entitled "Monographie du Stereoscope," by H. De la Blanchère (Paris, 186I), as also in the Cosmos.

The use of the stereoscope, whether catoptric, dioptric, or diaphragmatic, would have remained pretty restricted, if photography had not come in to greatly extend that use, in its application to industries, arts, and sciences.

When one undertakes to study the hyperoptics, it often happens that the vibrations of the molecules of ether, constituting a luminous wave, are found difficult to conceive, 
To remove this difficulty, Wheatstone invented a very ingenious apparatus, by which the vibratory motions of the luminiferous ether could be represented with considerable fidelity, and especially the phenomena of polarisation, whether rectilinear, circular, or elliptic.

Many were the achievements realised by Wheatstone in applying himself to optics: we owe to him the invention of a kaleidoscope, in which the persistence of impressions on the retina was utilised in demonstrating the transversal vibrations of an elastic rod fixed at one of its extremities; we owe to him one of the most sensitive photometers, as also the way of estimating the duration of lamps, the movements of the sea, and the ramifications of the retina; the difference between the solar and the electric light, and the lines of the light obtained from combustion of bodies brought to the poles of the voltaic battery. $\mathrm{He}$ was, further, the inventor of the polar clock, an instrument designed to indicate the hours through observation of the plane of polarisation of light of the blue sky in the region of the North Pole. That instrument, improved by Soleil, was marvellously adapted for finding the neutral points of Arago, Babinet, and Brewster.

The science of acoustics also profited by the valuable researches of our Lincean correspondent, for he experimented on sound and on hearing, devised his kaleidophone, occupied himself with resonance or reciprocal vibrations produced by a column of air; he also studied the transmission of musical sounds, and the figures obtained with sand on a vibrating surface, or acoustic figures.

Moreover, he cultivated, with great advantage to science, electro-dynamics; and devised two rheostats, one for great, the other for small resistances.

We are indeited to the illustrious deceased for mariy other scientific contributions, which have realised a notable progress in various branches of modern physics, and especially in telegraphy. Among these contributions, which time would fail fully to enumerate, we must not omit to speak of the method, so fruitful of valuable consequences, by which Wheatstone determined the velocity of the electric discharge in a metallic wire.

$\mathrm{He}$ was likewise skilled and practised in ballistics; and he employed the uniform rotation of two pasteboard discs, fixed on a common horizontal axis passing through their centres, to ascertain the initial velocity of a projectile fired from a gun. The projectile, traversing with uniform velocity these rotating discs, produced within two holes, the different situations of which afforded a means of determining the initial velocity of the ball.

Wheatstone was the first to employ the rapid rotation of a reflecting disc for measuring the velocity of propagation of an imponderable agent, without resorting to great distances, such as the planetary. After having in vain turned the spark-exciting organ round an axis, hoping to be able to increase the extent of sparks, and also to alter their direction, according to the direction of turning, he conceived the idea of communicating to a reflecting disc or plane mirror a very rapid rotatory action, by which the electric spark produced at a certain distance from the disc might be reflected.

The interesting consequences derived from these experiments are-( 1 ) that electricity takes an appreciable time in traversing a distance, whence may be inferred approxi- mately the velocity of the electric current; (2) that this velocity does not depend on the direction of the electric current; (3) that of three sparks, reflected by this means, in the same horizontal direction, the two lateral ones appear contemporaneously, but the middle appears retarded with respect to the first, which fact is not reconcilable with the hypothesis of Franklin on the nature of electricity ; (4) that the same method was adopted by the celebrated Arago, whose experiments lead to a decisive judgment which of the two theories on the nature of light, that based on emanation, or that based on ethereal vibration, must prevail.

The fact that we now possess methods of determining the velocity of light so practical, elegant, and speedy as those of the distinguished physicists Fizeau and Foucault, is due to the method of rotating mirrors, which was introduced through this order of researches of the English physicist, of whom we deplore being for ever bereaved; the fame of whose discoveries is everywhere-

"And with the world itself shall still endure."

Dante, Inf., ii. v. 60.

P. VOLPICELLI

\section{THE PROGRESS OF THE LOAN COLLECTION}

JARIOUS are the trains of thought suggested by a visit to those galleries in which the science of the past and the present is being represented by so goodly an array of its working implements. If one has been at all in sympathy with the movement which is now so near its goal (and who that has in the least appreciated the progress and benefits of science can be out of sympathy with it?), it will, first of all, be truly gratifying to him to observe on every hand such manifest tokens of hearty co-operation in the movement. Even those who are engaged in marshalling the various treasures of thie departments which have been entrusted to their charge seem to be animated with an unusual zeal (a zeal promising the best results), and, at first sight even, it is evident that the various museums and private collections in this country and on the Continent have been ransacked for some of their choicest contents to be sent to these South Kensington galleries, aiding the completion of an ideal which is true in its comprehensiveness. The nations of the Continent who were appealed to for their support of the scheme, have shown, many of them, by an activity which is beyond all praise, how warmly the proposal has been entertained. This is especially true of Germany. The Berlin Committee appointed a short time ago, and including some of the foremost names in science; while it gained also the useful accession of Imperial influence, promptly made application (the time was short) to the various Universities and Polytechnic Schools throughout the country, and they were met as promptly; so that soon quite a network of subordinate committees came into being, all working harmoniously towards the comimon end. The German contributions form a very considerable proportion of the whole ; and they, in common with contributions from the Continent generally, are indeed surprising in their extent; if we consider the shortness of time allowed and the unique character of the exhibition. Both Germans and French have been doing all that they 